\title{
Penguasaan dan Pengembangan Iptek Kemaritiman Guna Mewujudkan Indonesia Sebagai Poros Maritim Dunia
}

\author{
Widodo ${ }^{1}$, Adi Bandono ${ }^{2}$, \\ ${ }^{1}$ Universitas Pertahanan \\ Kawasan IPSC Sentul Sukahati Citeureup Kabupaten Bogor 16810 Jawa Barat \\ ${ }^{2}$ Sekolah Tinggi Teknologi Angkatan Laut \\ Bumimoro Morokrembangan Kota Surabaya 60178 Jawa Timur \\ *adibandono@gmail.com \\ DOI: https://doi.org/10.21107/rekayasa.v14i3.12566
}

\begin{abstract}
Science and technology is always experiencing dynamics in the form of changes and developments. Industrial revolution 4.0. has brought new technology which is always characterized by cyber physical systems such as artificial intelligence, advance robotics, autonomous vehicles, $3 d$ printing, virtual reality, and crypto currency, and others. The impact of the presence of these new technologies brings major and fundamental changes in various fields of life, including the maritime sector. The industrial revolution 4.0., has given rise to the phenomenon of shifting community activities which were initially carried out in the real world, now carried out in cyberspace. Everything is digital and all activities are done online with the help of internet media. In realizing the vision of the five pillars of PMD through the mastery and development of science and technology, several strategies are needed, including: (1) Building a maritime culture, through efforts: (a) the use and application of smart education technology, (b) carry out a cultural revolution or mental revolution, (c) build and expand internet network access infrastructure that is evenly distributed and reaches all regions of Indonesia. (2) Utilization of Maritime Natural Resources, with strategies, including: (a) Increasing the quantity and quality of exploration and management of natural resources classified as potential recoverable resources. (b) Increase the quantity and quality of exploration and management in the field of natural resources which are classified as potential non-recoverable resources, such as large oil and gas, minerals and mining materials. (c) Improving marine tourism management based on marine natural resources. (3) Development of Maritime Infrastructure and Connectivity, through efforts to prioritize the development of sea highways for inter-island domestic connectivity, by developing port infrastructure, and shipping and navigation safety infrastructure. (4) Improving Maritime Diplomacy, through strategies to strengthen diplomacy in the economic sector, diplomacy in the defense sector, and digital diplomacy. (5) Maritime Defense, through increasing the ability of defense equipment to defend the country's sovereignty, the territorial integrity of the Unitary State of the Republic of Indonesia, and the safety of all ethnic groups from all forms of threats.
\end{abstract}

Key words : maritime technology, industrial revelation, Indonesian Navy

\section{PENDAHULUAN}

Doktrin mengenai Indonesia sebagai Poros Maritim Dunia (PMD) sebenarnya telah lama dikumandangkan, yakni pada tahun 2014 yang silam, ketika Bapak Ir. Joko Widodo dilantik sebagai Presiden RI ke-7 dalam masa pemerintahan periode pertama. Beliau bahkan menjadikan gagasan PMD tersebut sebagai visi Pemerintahannya, yang tidak hanya diperkenalkan di wilayah domestik saja, namun juga dikumandangkan ke seluruh negara-negara di dunia. Pada berbagai kesempatan Presiden RI

\section{Article History:}

Received: August, 30 2021 ; Accepted: October, $27^{\text {th }} 2021$ Rekayasa ISSN: 2502-5325 has been Accredited by Ristekdikti (Arjuna) Decree: No. 23/E/KPT/2019 August 8th, 2019 effective until 2023 senantiasa mengutarakan tentang cita-cita bangsa Indonesia sebagai PMD, termasuk dalam acara Konferensi Tingkat Tinggi (KTT) Asia Timur di Nay Pyi Taw, Myanmar, Kamis, 13 November 2014 dan kegiatan konferensi internasional lainnya (Puspita Sari, 2014). Pencanangan doktrin PMD tersebut merupakan penegasan, penguatan sekaligus implementasi dari Deklarasi Djuanda 1957 tentang Konsepsi Wawasan Nusantara dan United Nations Convention on the Law of the Sea (UNCLOS) 1982

\section{Cite this as:}

Widodo., Bandono, A \& Suharyo, O.S. (2021). Penguasaan dan Pengembangan IPTEK Kemaritiman Guna Mewujudkan Indonesia sebagai Pros Maritim Dunia. Rekayasa 14 (3). 319-327. doi: https://doi.org/10.21107/rekayasa.v14i3.12566. 
yang menempatkan Indonesia sebagai negara kepulauan dengan potensi maritim yang sangat besar. Poros Maritim Dunia merupakan visi pembangunan nasional jangka panjang sebagai upaya membangun Indonesia menjadi negara kepulauan yang berorientasi maritim. Letak geostrategis dan tinjauan sejarah bangsa menjadi pijakan yang kuat dalam mencapai visi Indonesia sebagai Poros Maritim Dunia.

Dalam kebijakan PMD yang dicanangkan, terdapat lima pilar utama yang menjadi prioritas untuk diwujudkan, meliputi: (1) pembangunan budaya maritim Indonesia, (2) menjaga laut dan sumber daya laut dengan fokus membangun kedaulatan pangan laut melalui pengembangan industri perikanan dengan menempatkan nelayan sebagai pilar utama, (3) memberikan prioritas pada pengembangan infrastruktur dan konektifitas kemaritiman dengan membangun tol laut, pelabuhan laut, logistik dan industri perkapalan serta pariwisata kemaritiman, (4) memperkuat diplomasi maritim yang mengajak semua mitra Indonesia untuk bekerjasama pada bidang kelautan, dan (5) membangun kekuatan pertahanan maritim untuk menjaga kedaulatan dan kekayaan maritim serta bentuk tanggungjawab dalam menjaga keselamatan pelayaran dan keamanan maritim.

Doktrin PMD ini ternyata seiring dengan teori kejayaan maritim yang dikemukakan oleh Mahan dan Corbett. A.T. Mahan dalam Adam KR (2003) mengemukakan tentang dasar strategi maritim negara-negara besar dalam mencapai status sebagai negara maritim yang ideal. Mahan merumuskan ada enam karakter yang menjadi syarat sebuah negara potensial untuk mengembangkan sea power. Keenam karakter tersebut, meliputi (1) Geographical position (posisi geografis), (2) Physical conformation (bentuk fisik), (3) Extent of territory (luasnya wilayah), (4) Number of population (jumlah penduduk), (5) National character (karakter bangsa), dan (6) Character of government (karakter Pemerintah). Negara yang memiliki pemerintahan yang kuat dengan penerapan kebijaksanaan yang tegas akan memberikan manfaat untuk menjadi sebuah kekuatan dalam perubahan dari negara berkembang menjadi negara maju. Lautan yang luas hanya dapat dikendalikan sepenuhnya melalui upaya pembangunan kekuatan Angkatan Laut yang kuat. Ketika Angkatan Lautnya kuat akan memberikan deterrent effect bagi negara lain yang kemungkinan ingin mengganggu atau berusaha menginvasi.

Dalam rangka mewujudkan visi nasional jangka panjang PMDnya, Indonesia dapat bercermin dan belajar dari keberhasilan beberapa negara maju yang telah mampu mengelola aset maritimnya, seperti: Inggris yang menguasai aspek keuangan dan regulasi, Amerika Serikat yang menguasai aspek militer hampir seluruh Sea Lines of Communications atau SLOCs, Korea selatan mampu tampil sebagai raksasa galangan kapal dunia, Denmark mampu mengontrol 15\% kapasitas kapal kontainer global melalui Maersk Group, Singapura dengan port of Singapore Authority mampu memainkan peran sebagai operator pelabuhan terbesar dunia. Indonesia dengan modal letak geografis yang strategis, sumber daya alam yang melimpah dan bonus demografi yang menyertainya itu tentu harus lebih mampu dalam mengelola semua potensi tersebut menjadi suatu kekuatan geostrategis, geoekonomi dan geopolitik. Peluang sebagai pusat ekonomi dunia yang diramalkan akan bergeser dari kawasan Eropa-Amerika menuju ke kawasan Asia-Pasifik akan lebih mudah ditangkap oleh Indonesia sehingga mampu tampil sebagai negara maritim yang besar.

Selanjutnya untuk dapat mengamankan kebijakan PMD agar dapat diwujudkan maka doktrin PMD tersebut kemudian dituangkan ke dalam Peraturan Presiden Nomor 2 Tahun 2015 tentang Rencana Pembangunan Jangka Menengah Nasional (RPJMN) 2015 - 2019. Kebijakan tersebut diperkuat lagi ke dalam Peraturan Presiden Nomor 16 Tahun 2017 tentang Kebijakan Kelautan Indonesia, dimana ditegaskan bahwa PMD merupakan visi Indonesia untuk menjadi sebuah negara maritim yang berdaulat, maju, mandiri, dan kuat serta mampu memberikan kontribusi positif bagi keamanan dan perdamaian kawasan serta dunia yang sesuai dengan kepentingan nasional. Dalam proses perjalanan implementasi kebijakan PMD di lapangan memang muncul banyak permasalahan dan tantangan yang harus dihadapi oleh Pemerintah Indonesia, namun melalui komitmen, kerja keras, upaya yang terencana, sistematis, bertahap dan berkesinambungan, maka kebijakan PMD pada periode 2015-2019 tersebut dikatakan dapat berjalan dengan baik meskipun masih belum optimal.

Ilmu Pengetahuan dan Teknologi senantiasa mengalami dinamisasi berupa perubahan dan 
perkembangan dari waktu ke waktu. Perubahan dan perkembangan iptek saat ini sudah berada di era revolusi industri 4.0. Avando Bastari (2019) mengemukakan bahwa revolusi industri 4.0 telah membawa teknologi baru yang selalu ditandai dengan system cyber physical seperti artificial inteligence, advance robotic, autonomous vehicle, $3 d$ printing, virtual reality, dan crypto currency, dan lain lain. Dampak kehadiran teknologi baru tersebut selalu membawa perubahan besar dan mendasar pada berbagai bidang kehidupan, termasuk bidang kemaritiman. Revolusi industri 4.0., telah memunculkan fenomena pergeseran aktifitas-aktifitas masyarakat yang pada awalnya dilakukan di dunia nyata kini dilakukan di dunia maya. Semua serba digital dan seluruh aktifitasnya menggunakan daring berbantuan media internet. Kreasi berbagai inovasi baru dalam teknologi digital secara langsung dapat mempengaruhi pergeseran tatanan kehidupan sosial dalam masyarakat, termasuk masyarakat maritim. Mengenai kemampuan kreasi berbagai inovasi baru, tampaknya masyarakat di Indonesia mengalami sedikit ketertinggalan dalam mengantisipasinya.

\section{Identifikasi Kekuatan, Kelemahan, Peluang dan Ancaman Dalam Mewujudkan PMD a) Kekuatan}

Negara Indonesia secara alamiah terletak pada posisi geografis yang sangat strategis, di mana secara astronomi terletak antara $60^{\circ} \mathrm{LU}-11^{\circ} \mathrm{LS}$ dan $95^{\circ} \mathrm{BT}-141^{\circ} \mathrm{BT}$, wilayahnya terbentang luas di antara dua samudera (Samudera Hindia dan Samudera Pasifik), dan berada di antara dua benua yang besar, yaitu Benua Asia dan Australia (Gambar 1). Letak strategis yang dimiliki Indonesia tersebut, menjadikan Indonesia sebagai negara yang berada di persilangan lalu lintas perdagangan dunia, yang dapat ditempuh baik melalui udara maupun laut. Luas wilayah perairan laut Indonesia tercatat mencapai kurang lebih 7,9 juta $\mathrm{km}^{2}$ (termasuk Zona Ekonomi Eksklusif Indonesia).

Panjang garis pantai yang mengelilingi Nusantara kurang lebih $81.000 \mathrm{~km}^{2}$, dan merupakan yang terpanjang kedua di dunia setelah Amerika Serikat (Pramono, 2005). Adapun jumlah pulau-pulau di Indonesia berdasarkan perhitungan yang dilakukan oleh Dinas Hidro Oseanografi pada tahun 1982 yang disampaikan dalam Rapim ABRI tahun 1987 dan dikukuhkan melalui Surat Menhankam pangab Nomor B/858/M/IX/1987 tanggal 9 Nopember 1987 pulau di Indonesia berjumlah 17.508 pulau. Namun dengan lepasnya Sipadan dan Ligitan serta Timor Leste maka berkurang 4 pulau (P. Sipadan, P. Ligitan, P. Kambing atau Atauro, dan P. Yako). Selanjutnya terdapat 5 pulau (P. Dapur, P. Ubi Kecil, P. Ubi Besar, P. Nirwana, P. Ayer Kecil) di teluk Jakarta yang hilang karena mengalami abrasi. Sehingga sampai saat ini berdasarkan Surat Kadishidros Nomor SE/1241/IV/2012 tanggal 10 April 2012, jumlah pulau menjadi 17.499 pulau, yang terdiri dari 13.466 pulau bernama dan 4.033 pulau belum bernama.

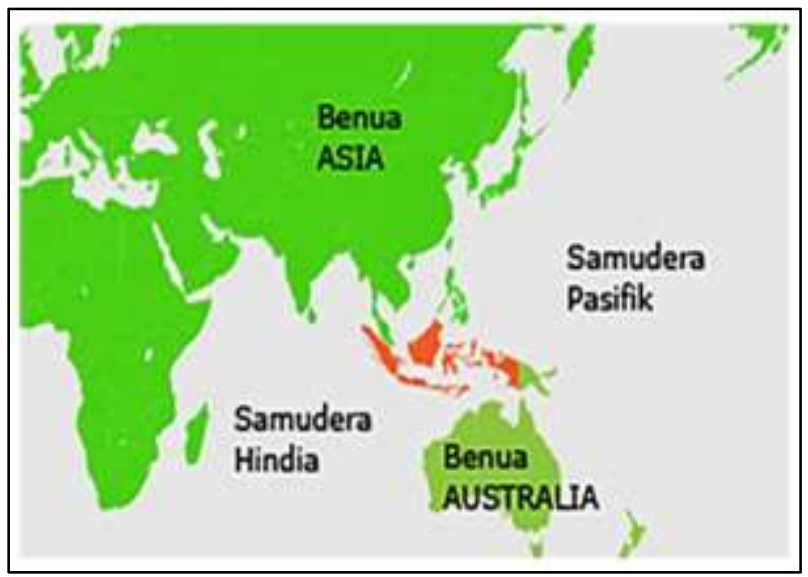

Gambar 1. Posisi Geografis Indonesia

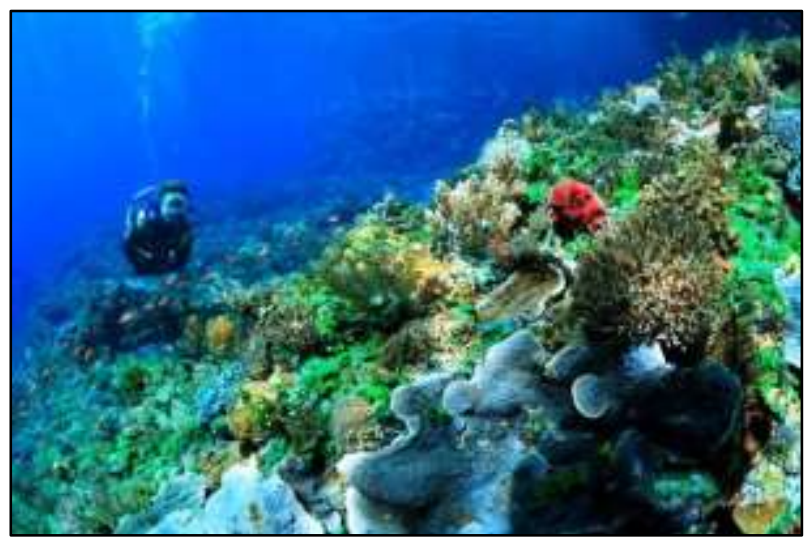

Gambar 2. Ilustrasi Kekayaan Terumbu Karang di Indonesia

Indonesia didukung dengan iklim yang tropis, sehingga terdapat dua musim, yaitu musim penghujan dan musim kemarau. Daratannya dipenuhi dengan berbagai macam tumbuhan dan hewan sebagai bahan makanan yang berlimpah. Tanahnya sangat subur untuk ditanami, seperti: beras, jagung, sayur sayuran, buah-buahan, karet, kopi, gula, tembakau dan lain-lain. Demikian juga dengan kekayaan alam lautnya, yang sangat kaya 
dengan berbagai macam ikan, hewan laut dan sumber daya mineral (Gambar 2). Potensi sumber daya mineral kelautan banyak tersebar di seluruh wilayah perairan Indonesia. Sumber daya mineral ini diantaranya minyak dan gas bumi, timah, emas dan perak, pasir kuarsa, monasit dan zirkon, pasir besi, agregat bahan konstruksi, posporit, kromit, dan masih banyak lagi yang lainnya. Potensi laut Indonesia menurut perkiraan Lembaga Ilmu Pengetahuan Indonesia (LIPI) jika dihitung dalam konversi rupiah mencapai Rp. 1.772 trilyun (Purningsih, 2019).

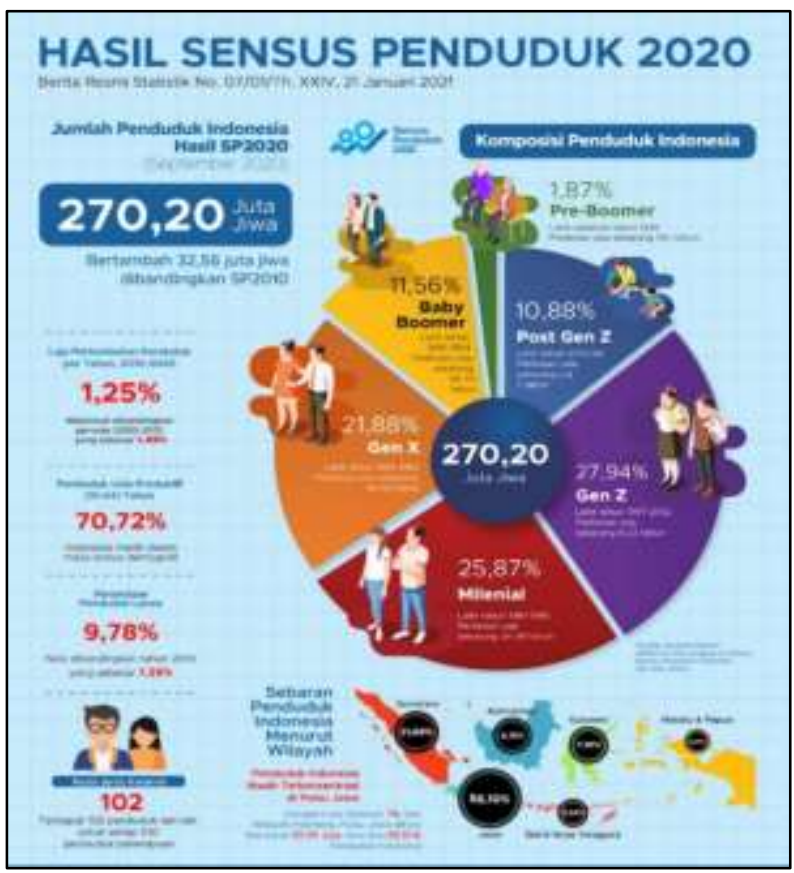

Gambar 3. Hasil Sensus Penduduk 2020

Pada era tahun 2030 sampai dengan 2040 diperkirakan Indonesia akan mengalami ledakan jumlah penduduk, dimana jumlah penduduk pada usia produktif yaitu usia 15 sampai dengan 64 lebih besar jumlahnya dibandingkan dengan jumlah penduduk pada usia yang tidak produktif yakni di bawah usia 15 dan di atas 65 (Gambar 3). Data jumlah penduduk Indonesia berdasarkan sensus penduduk tahun 2020 menunjukkan angka mencapai 270.203.917 jiwa, jadi jumlahnya bertambah 32.562 .591 jiwa dibandingkan sensus penduduk tahun 2010 atau rata-rata 3,26 juta jiwa per tahun. Dari jumlah seluruh penduduk Indonesia tersebut, 70,72\% merupakan penduduk usia produktif dengan umur 15 sd 65 tahun (BPS, 2021). Penduduk usia produktif yang dimaksud adalah mereka yang sekarang ini disebut sebagai generasi $Z$ dan generasi milenial. Manfaat bonus demografi bisa didapatkan Indonesia apabila penduduk usia produktif dapat memenuhi beberapa syarat, yakni sehat, terdidik, produktif, bekerja di sektor-sektor yang dibayar, dan berinvestasi.

\section{b). Kelemahan}

Posisi geografis yang strategis dan luasnya wilayah lautan membuat perairan Indonesia sebagai wilayah yang sangat rawan terjadinya pelanggaran oleh kapal-kapal yang berbendera asing, pencurian ikan ilegal, penyelundupan, transhipment ilegal, narkoba, dll. Disamping itu, ramainya perdagangan internasional melalui laut, utamanya ketika melalui ALKI yang telah ditetapkan oleh Pemerintah Indonesia, membutuhkan kondisi yang aman dari gangguan pembajakan. Pemerintah dalam hal ini Bakamla merilis setidaknya terdapat 318 jenis kerawanan di perairan Indonesia sepanjang tahun 2020 yang meningkat dari tahun sebelumnya yakni 265 (CNN Indonesia, 2020). Destructive Fishing Watch (DFW) Indonesia mencatat setidaknya terdapat 12 kejahatan maritim yang terjadi pada sepanjang bulan Januari 2021 (DFW, 2021). Pemerintah Indonesia harus mampu menjamin kondisi aman tersebut. Keterbatasan jumlah alutsista yang dimiliki oleh TNI $\mathrm{AL}$, masih belum terkoordinasikannya dengan baik satuan- satuan kerja yang berkepentingan dalam menangani permasalahan di lautan, belum adanya integrasi dalam satu jaringan informasi yang terpadu, menjadi penyebab masih lemahnya sistem keamanan dan pertahanan wilayah laut Indonesia.

Potensi sumber daya laut yang berlimpah belum diimbangi dengan kemampuan eksplorasi dan eksploitasi yang maksimal, sehingga potensi laut yang termanfaatkan masih sangat minim baik dalam kuantitas maupun kualitasnya. Potensi sumber daya laut yang bernilai ekonomi yang mampu dieksplorasi dan eksploitasi masih berkisar di bawah angka 30\% (Putuhena, 2019). Kondisi tersebut tentu saja sangat memprihatinkan dan masih jauh dari harapan. Sebenarnya, Indonesia sejak Pemerintahan Susilo Bambang Yudoyono (2010) telah memiliki program untuk peningkatan potensi sumber daya laut berupa proyek Lumbung Ikan Nasional (LIN) di wilayah Maluku sebagai pilot projek. Namun ternyata proyek yang sangat strategis tersebut tampaknya belum bisa berkembang dengan optimal, karena banyak mengalami kendala, diantaranya: rendahnya kualitas SDM, ketersediaan armada, pasokan bahan bakar, sumber listrik, pasokan rantai dingin, 
koperasi nelayan dan interkoneksi pemasaran (Kiehara, 2021). Pada akhir tahun 2021 ini, oleh Pemerintahan Joko Widodo, program LIN digalakkan kembali.

\section{c). Peluang}

Posisi alamiah dari letak geografis yang sangat strategis sangat menguntungkan bagi Indonesia karena berada pada titik persilangan kegiatan ekonomi dunia, di mana terjadi perdagangan yang intensif antara negara-negara maju dengan negara-negara berkembang. Perdagangan antara Jepang, Korea dan China dengan negara-negara di Asia, Afrika, Australia dan Eropa, pasti melewati jalur Alur Laut Kepulauan Indonesia (ALKI) yang telah ditetapkan. Letak geografis yang sangat strategis memberikan peluang besar bagi Indonesia untuk menjadi pusat ekonomi dunia yang diramalkan akan bergeser dari kawasan Eropa-Amerika menuju ke kawasan Asia-Pasifik. Ditinjau dari aspek geopolitik, letak geografis Indonesia sangat menguntungkan dan memberikan peluang besar bagi Indonesia untuk dapat menjalin, membangun dan membina hubungan baik (bilateral, multilateral) dengan negara-negara di sekitar perbatasan, kawasan regional maupun dunia global. Indonesia pun akan lebih memiliki peranan penting dalam percaturan politik luar negeri yang bebas aktif dalam rangka membangun ekonomi nasional dan ikut serta dalam menjaga keamanan dan perdamaian dunia.

\section{d). Ancaman}

Indonesia dengan wilayah yang sangat luas namun jika Pemerintah tidak mampu mengendalikannya dengan baik maka akan memunculkan kerawanan bahkan ancaman nyata utamanya pada keamanan dan pertahanan negara. Intervensi dari negara asing yang ingin menguasai baik secara budaya, ekonomi maupun politik tidak menutup kemungkinan terjadi jika Indonesia sendiri tidak mampu menjaga keamanan di dalam negeri agar tetap kondusif dan apalagi untuk mempertahankan kedaulatan wilayah.

Sumber daya alam maritim Indonesia jika tidak dijaga dengan baik akan menjadi incaran negara lain untuk diekplorasi dan dieksploitasi secara ilegal, seperti illegal logging, illegal fishing, penyelundupan, transhipment illegal, dll. Disamping itu juga akan muncul ancaman yang sedang menjadi sorotan saat ini yaitu ancaman terhadap sumber daya laut (national resources turbulation), berupa pencemaran dan pengrusakan terhadap ekosistem laut dan sumber daya alam.

\section{Revolusi Industri 4.0 dan Perkembangan Terkini IPTEK Terkini}

Revolusi industri 4.0., merupakan fenomena era yang tidak bisa dihindari dan pengaruhnya sangat besar bagi perkembangan dunia industri termasuk perubahan perilaku individual dan sosial dalam kehidupan masyarakat. Pada era tersebut semua teknologi beralih ke arah digital, dimana manusia dipaksa berinteraksi secara penuh dengan teknologi. Revolusi Industri 4.0. merupakan fenomena perpaduan antara teknologi siber dengan teknologi otomatisasi. Revolusi Industri 4.0 juga dikenal dengan istilah "cyber physical system", di mana konsep aplikasinya berpusat pada otomatisasi dan didukung oleh teknologi informasi yang berkembang dengan pesat, sehingga keterlibatan tenaga manusia menjadi semakin berkurang. Melalui pendayagunaan teknologi digital, maka efektivitas, efisiensi dan produktifitas kinerja dalam suatu lingkungan kerja dengan sendirinya bertambah meningkat. Revolusi Industri 4.0, kini telah melahirkan sekitar sembilan pilar utama jenis teknologi digital yang siap menggantikan teknologi lama. Teknologi tersebut kini berkembang dalam berbagai bidang kehidupan manusia (Gambar 4).

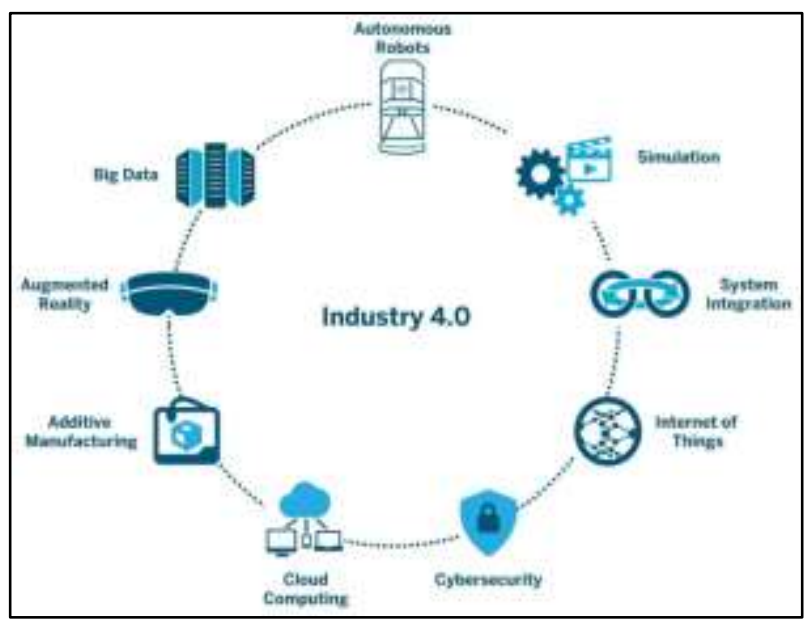

Gambar 4. Sembilan Pilar Teknologi Revolusi Industri 4.0 
Strategi Penguasaan dan Pengembangan Iptek untuk Mewujudkan Poros Maritim Dunia (PMD)

Banyak para ahli dari berbagai disiplin ilmu yang meramalkan bahwa Indonesia akan mengalami mengalami lompatan jauh dengan masuk ke dalam jajaran sebagai 5 negara besar yang memiliki perekonomian terkuat di dunia pada tahun 2030-2040. Terdapat empat aspek untuk bisa melakukan lompatan jauh ke depan, yaitu dengan meningkatkan dan mengembangkan teknologi, industri, inovasi dan sumber daya manusia (SDM). Bahkan lompatan teknologi digital yang dilakukan di Indonesia pada Konferensi Tingkat Tinggi (KTT) G20 (Group of Twenty) di Kota Roma, Italia, pada 30-31 Oktober 2021 baru lalu, mendapatkan apresiasi yang tinggi dari para pemimpin dunia (Kemlu, 2021). Oleh karena itu, Indonesia perlu memulainya dengan membuat peta jalan sebagai agenda nasional, strategi dan arah yang jelas guna melakukan lompatan yang jauh ke depan untuk memacu pencapaian kedaulatan maritim melalui PMD.

\section{a). Membangun Budaya Maritim Indonesia}

Membangun kembali budaya maritim bangsa Indonesia salah satunya adalah melalui suatu proses pendidikan berbasis kemaritiman yang berkualitas, bertahap dan berkelanjutan, yang diterapkan pada semua jenjang dan jenis pendidikan formal, baik pada jenjang dan jenis pendidikan anak usia dini (Pendidikan Anak Usia Dini, Kelompok Bermain, Taman Kanak-Kanak), pendidikan dasar (MI/SD, MTs/SMP), pendidikan menengah (MA/SMA/SMK) maupun pendidikan tinggi (PTN/PTS). Pendidikan berbasis kemaritiman bisa juga ditempuh melalui jalur pendidikan nonformal dan informal sebagai strategi pendidikan yang mampu menumbuhkan kesadaran dan pembiasaan untuk mencintai tanah air sepenuhnya. Melalui aplikasi proses pendidikan berbasis kemaritiman tersebut diharapkan paradigma kontinental semakin terkikis dan paradigma maritim dapat semakin tumbuh dan berkembang dalam jiwa setiap Warga Negara Indonesia. Keberhasilan menumbuhkembangkan karakter kebaharian dalam setiap Warga Negara Indonesia, akan membawa bangsa Indonesia menuju Poros Maritim Dunia yang dicita-citakan.

Pemerintah perlu membangun dan memperluas infrastruktur akses jaringan internet yang merata dan menjangkau ke seluruh wilayah Indonesia yang mencakup ke seluruh daerah-daerah yang terpencil, terdepan dan terluar (3T), sehingga setiap warga negara Indonesia dapat memperoleh akses informasi dan data tentang kemaritiman yang sama serta mampu membangun kompetensi literasinya secara mandiri

\section{b). Pendayagunaan Sumber Daya Alam Maritim}

Potensi sumber daya alam kemaritiman merupakan modal dasar yang utama untuk membangun kekuatan perekonomian nasional bangsa Indonesia. Peningkatan perekonomian nasional sudah pasti akan seiring dengan peningkatan taraf kehidupan, kesejahteraan dan kemakmuran sehingga dapat digunakan sebagai landasan untuk membangun kembali kejayaan bangsa Indonesia sebagai bangsa maritim. Lautan yang mendominasi 2/3 luas wilayah Indonesia, jika kekayaan alamnya yang luar biasa besar tersebut dapat dikelola dengan baik dan benar serta professional dengan berorientasi kepada kesejahteran, kelestarian dan keberlanjutan maka akan menghasilkan nilai ekonomi tinggi untuk menopang pembangunan nasional yang kini sedang digalakkan. Beberapa strategi yang dapat ditempuh dalam mengelola sumber daya alam maritim secara efektif dan efisien sehingga menjadi sumber kesejahteraan dan kemakmuran bangsa.

\section{c). Pengembangan Infrastruktur dan Konektifitas Kemaritiman.}

Pemerintah telah mencanangkan keinginan untuk menjadikan Indonesia sebagai Poros Maritim Dunia memprioritaskan pengembangan tol laut untuk konektivitas domestik antar pulau. Oleh karena itu dibutuhkan infrastruktur yang mendukung konektivitas domestik antar pulau sehingga dapat mempercepat dan memperluas pembangunan ekonomi Indonesia. Penyediaan infrastruktur yang mendorong konektivitas akan berdampak menurunkan biaya tranportasi dan logistik sehingga dapat meningkatkan daya saing produk dan mempercepat gerak ekonomi. Beberapa infrastruktur maritim yang perlu mendapatkan prioritas, meliputi infrastruktur pelabuhan dan infrastruktur keselamatan pelayaran dan navigasi.

Untuk menyatukan kekuatan dan potensi antar koridor, maka diperlukan infrastruktur pendukung yang berperan sebagai pemerkuat konektivitas nasional. Sistem Logistik Nasional menjelaskan terdapat beberapa jalur konektivitas nasional yaitu 
Short Sea (coastal) Shipping, Jalur Laut Nasional Primer (trunk), Jalur Laut Nasional Sekunder dan Jalur Utama Darat.

Strategi berikutnya adalah penerapan National Logistic Ecosystem (NLE) sebagai bentuk upaya reformasi di bidang logistik nasional guna meningkatkan kinerja sistem logistik, memperbaiki iklim investasi, dan meningkatkan daya saing ekonomi. Pada hakikatnya, NLE mengenalkan suatu konsep kolaborasi digital yang memungkinkan entitas logistik terhubung dengan pemerintah dan platform logistik lainnya. NLE merupakan kolaborasi yang luas antara seluruh $\mathrm{K} / \mathrm{L}$ yang terkait dengan arus logistik barang, sistem perbankan, transportasi pergudangan, dan lembaga lain yang termasuk dalam NLE.

NLE mencakup seluruh proses dari hulu hingga ke hilir dan arus logistik barang domestik ataupun internasional. Sistem NLE diharapkan dapat mempermudah eksportir, importir, atau pelaku logistik karena tidak perlu lagi memasukkan data secara berulang ke K/L yang berbeda-beda. Selain itu, NLE membuat proses bisnis lebih efisien melalui kolaborasi platform dengan penyedia transportasi, shipping, gudang, dan akses layanan lainnya. Penerapan NLE telah memiliki landasan kebijakan yaitu berdasarkan Instruksi Presiden (Inpres) Nomor 5 tahun 2020 tentang Ekosistem Logistik Nasional atau National Logistic Ecosystem (NLE) (Kemenko Marves, 2021).

\section{d). Diplomasi Kemaritiman}

Diplomasi merupakan salah satu cara yang dapat dilakukan oleh seluruh instrumen kekuatan militer maupun non militer nasional. Diplomasi sesungguhnya lebih efisien jika dilakukan secara bersama-sama oleh seluruh instrumen kekuatan nasional dalam varian yang lebih berorientasi pada perdamaian, persahabatan dan hubungan kerjasama lainnya, seperti: Pameran bendera, port visit, latihan bersama, patroli bersama, navy to navy talk, membangun kapasitas, kegiatan kemanusian, dll. Dalam era globalisasi saat ini perkuatan diplomasi dapat dilakukan dengan meningkatkan kerjasama antar negara baik yang bersifat bilateral maupun multilateral. Diplomasi maritim perlu diperkuat dalam rangka menjadikan Indonesia sebagai poros maritim dunia. Sebagai negara middle power, Indonesia harus mampu memainkan perannya baik di kawasan maupun dunia. Asean harus tetap menjadi prioritas politik luar negeri. Selain itu, Indonesia harus mampu memainkan perannya dalam ikut menjaga satu tatanan dunia yang demokratis, mempersempit gap kemakmuran antar bangsa, pergaulan dunia yang saling menghormati, aman dan stabil. Indonesia perlu meningkatkan konstribusi dalam menjaga perdamaian dan keamanan dunia.

\section{e). Pertahanan Maritim}

Pertahanan negara merupakan segala usaha untuk mempertahankan kedaulatan negara, keutuhan wilayah NKRI, dan keselamatan segenap suku bangsa dari segala bentuk ancaman. Pertahanan maritim terkait erat dengan keamanan maritim. Dinamika perkembangan lingkungan strategis utamanya kawasan Asia Tenggara menimbulkan dampak positif dan negatif sekaligus. Dampak positif yang tampak menonjol adalah pada aspek ekonomi, dimana terjadi peningkatan aktifitas seaborne trade secara signifikan yang mampu memicu pertumbuhan ekonomi regional bahkan global. Sedangkan dampak negatif yang tampak adalah semakin tingginya ancaman keamanan maritim di perairan Indonesia dan sekitarnya, seperti sengketa teritorial, ancaman transnasional crimes termasuk instabilitas keamanan negara-negara kawasan sebagai akibat dari aktivitas illegal. Termasuk konflik di Laut Cina Selatan, yang diklaim oleh enam Negara pantai yakni China, Taiwan, Vietnam, Filipina, Malaysia dan Brunai Darrusalam sebagai wilayah territorial mereka, sehingga perlu menjadi perhatian besar karena sangat berpengaruh terhadap pertahanan maritim Indonesia.

\section{KESIMPULAN}

TNI AL memiliki posisi dan peran yang sangat strategis dalam mengamankan kepentingan nasional sebagaimana diatur dalam pasal $9 \mathrm{UU}$ Nomor 34 tahun 2004 tentang TNI dan Peraturan Presiden Nomor 7 tahun 2008 tentang Kebijakan Umum Pertahanan Negara, namun pada sisi lain harus pula mengakomodasi UNCLOS 1982 yang mengatur tentang rezim lintas damai, lintas transit dan lintas alur laut kepulauan. Dalam rangka mengamankan peran dan strategi bangsa Indonesia menuju poros maritim dunia maka dibutuhkan peran TNI, khususnya TNI Angkatan Laut yang handal, disegani dan berkelas dunia (World Class Navy). Cita-cita menjadi world class navy harus terprogram secara gradual yang 
dimulai dari the way ahead as a world class navy, kemudian pursue as a world class navy dan terakhir adalah go forward as a world class navy. Inilah yang menjadi dasar bagi pembangunan TNI AL ke depan agar mampu mengamankan seluruh kebijakan dan aplikasinya dalam membangun Indonesia menjadi poros maritim dunia. TNI AL akan selalu hadir dalam setiap arena dalam melindungi kepentingan nasional.

\section{DAFTAR PUSTAKA}

Adams, KR., 2003. Attack and Conquer, International Anarchy and the OffenseDefense Deterrence Balance, International Security Winter 04. Vol. 28, No 8. Pp. 53.

Andi Taru NNW, 2019, Dampak Big Data pada Sistem Pemerintahan, diakses pada tanggal 30 Oktober 2021 dari laman https://www.gamelab.id/news/128-dampakbig-data-pada-sistem-pemerintahan.

Amanda Puspita Sari, 2014, Doktrin Poros Maritim Jokowi di Myanmar, CNN Indonesia, diakses pada tanggal 4 Oktober 2021 dari https://www.cnnindonesia.com/internasional/20 141113125042-106-11288/doktrin-porosmaritim-jokowi-di-myanmar.

Avando Bastari, 2019, Ancaman dan Peluang Lembaga Pendidikan Tinggi TNI Angkatan Laut di Era Disrupsi, Cakrawala TNI AL, Edisi 444, Dispenal Jakarta, hal. 28-32.

BPS, 2019, Jumlah Desa/Kelurahan Seluruh Indonesia, diakses pada tanggal 30 Oktober 2021 dari laman https:// www.bps.go.id/indikator/indikator/view data $\mathrm{p}$ ub/0000/api_pub/ bEVXU252 SU9HtjBxWEU3Z2N pS1ZPQT09/da_02/1

Badan Pusat Statistik, 2021, Hasil Sensus Penduduk 2020, Berita Resmi Statistik Nomor: 07/01/tahun XXIV/21 Januari 2021, diakses pada tanggal 18 Oktober 2021 dari laman https://www.bps.go.id/pressrelease/ 2021/01/21/1854/hasil-sensus-penduduk2020.html
CNBC Indonesia, 2020, Kualitas SDM Indonesia Kurang Optimal, diakses dari https:// www.cnbcindonesia.com/news/ 20200701184938-4-169544/kualitas-sdm-ribelum-optimal-nih-mas-nadiem pada tanggal 16 Oktober 2021.

Cyndi Mutia Annur, 2021, Jumlah Pengangguran Capai 8,75 Juta Orang per Pebruari 2021, diakses dari https://databoks.katadata.co.id/datapublish/20 21/05/05/jumlah-pengangguran-capai-875juta-orang-per-februari - 2021 pada tanggal 16 Oktober 2021.

Craig Eason, 2017, Video: Aughmented reality in marine simulation- a reality in dollar savings, diakses pada tanggal 20 Oktober 2021 dari laman https://fathom.world/augmented-realitymarine-simulation-reality-dollar-savings/

Dewi Purningsih, 2019, LIPI: Potensi Kekayaan Laut Indonesia Senilai Rp. 1.772 Trilyun, diakses tanggal $17 \quad$ Oktober 2021 dari https://www.greeners.co/berita/lipi-potensikekayaan-laut-indonesia-senilai-rp1-772-triliun.

Ditjen Hubla Kemhubla, 2020, Pengembangan Smart Port Dorong Terciptanya Keseimbangan Aspek Ekonomi dan Ekologi di Sektor Kepelabuhan, diakses pada tanggal 25 Oktober 2021 dari laman https://hubla.dephub.go.id/ksoppangkalanbun/ page/news/read/7579/pengembangan-smartport-dorong-terciptanya-keseimbangan-aspekekonomi-dan-ekologi-di-sektorkepelabuhanan.

ITGID, 2021, Cybersecurity yang sedang trend saat ini, diakses pada tanggal 30 Oktober 2021 dari laman https://itgid.org/the-top-five-cybersecurity-threats-to-watch-out-for-now/

Kemenlu RI, 2021, Indonesia Gaungkan Diplomasi Digital di Kawasan, diakses pada 12 Oktober 2021

dari https://kemlu.go.id/portal/id/read/584/berita/in donesia-gaungkan-diplomasi-digital-dikawasan.

Kemenlu, 2021, Indonesia ajak dunia berkolaborasi untuk pulih bersama di Presidensi 
G20 2022, diakses pada tanggal 2 November 2021 dari lamanhttps://kemlu.go.id/portal/id/read/2934/ berita/indonesia-ajak-dunia-berkolaborasiuntuk-pulih-bersama-di-presidensi-g20-2022.

Kemristekdikti, 2018, Daya Saing Inovasi Rendah, Indonesia Peringkat ke 87 dari 137, diakses dari https://risbang.ristekbrin.go.id/publikasi/beritamedia/daya-saing-inovasi-rendah-indonesiaperingkat-ke-87-dari-137/ pada tanggal 16 Oktober 2021.

Kemenko Marves, 2021, Kawal Penerapan National Logistic Ecosystem (NLE), Kemenko Marves Tinjau Pelabuhan Belawan, diakses pada tanggal 21 Oktober 2021 dari laman https:// maritim.go.id/kawal-penerapan-nationallogistic-ecosystem-nle-kemenko-marves.

Kominfo,2021, Kominfo Bangun 4200 BTS Demi Desa Teraliri Internet di 2021, diakses pada tanggal 30 Oktober 2021, dari laman https://www.kominfo.go.id/content/detail/3175 6/kominfo-bangun-4200-bts-demi-desateraliri-internet-di-2021/0/sorotan media.

Kompas, 2020. Apa Dampak Negatif Jika Generasi Muda Tidak Suka Buku?, Diakses dari alamat https://www.kompas.com/skola/read/2020/05/ 13/063500969/apa-dampak-negatif-jikagenerasi-muda-tidak-suka-membaca-bukujawaban-tvri?page $=$ all, pada tanggal 19 Oktober 2021.

Kompas, 2020, Potensi Sumber Daya Alam Lautan, diakses pada tanggal 28 Oktober 2021 dari laman

https://www.kompas.com/skola/read/2020/05/ 29/090000069/potensi-sumber-daya-alamlautan

Kominfo.go.id, 2021, Jadi Poros Maritim Dunia, Presiden: perlu kerja nyata, diakses pada tanggal 12 Oktober 2021 dari https://kominfo.go.id/content/detail/37136/jadi -poros-maritim-dunia-presiden-perlu-kerjanyata/0/ berita.
Leo Dwi Jatmiko, 2020, APJII, 196,7 Juta Warga Indonesia Sudah Melek Internet, di akses pada tanggal 30 Oktober 2021 dari laman https://teknologi.bisnis.com/read/20201110/10 1/1315765/apjii-1967-juta-warga-indonesiasudah-melek-internet.

Melanie, 2021, 12 Benefits of additive manufacturing and 5 disadvantages, diakses pada 30 Oktober 2021, dari laman website https://www.unleashedsoftware.com/blog/12benefits-of-additive-manufacturing-and-5disadvantages

Musliadi, 2016, Cerdas memanfaatkan Cloud Computing "Google drive", diakses pada tanggal 30 Oktober 2021 dari laman https://medium.com/@musliadi/cerdasmemanfaatkan-cloud-computing-google-drive$39 \mathrm{e} 2 \mathrm{ffa} 1247 \mathrm{a}$

Porttechnology.org, 2018, Port of the future in a new Ecosystem, diakses pada tanggal 1 November 2021 dari laman https://www.porttechnology.org/news/pti grant s free access to its_supply_chain_journal/

USDA, 2021, SWOT Analysis a tool for making better business decisions, United States Departement of Agriculture Risk Management Agency, USA.

VoaIndonesia, 2021, Sama, Skor Indeks Persepsi Korupsi Indonesia dan Gambia, diakses dari https://www.voaindonesia.com/a/sama-skorindeks-persepsi-korupsi-indonesia-dangambia/ 5756699. html, pada tanggal 16 Oktober 2021. Jurnal Legislasi Indonesia 